\title{
Irisin Signaling Pathway is up Regulated by Resistance Training in Ovariectomized Rats
}

\author{
Silva-Magosso $\mathrm{NS}^{1^{*}}$, Barbosa $\mathrm{MR}^{2}$, Tomaz $\mathrm{LM}^{3}$, Rodrigues $\mathrm{MFC}^{3}$, Magosso $\mathrm{RF}^{4}$, Canevazzi \\ GH$^{3}$, Souza MVC ${ }^{3}$, Assis RP ${ }^{4}$, Selistre-de-Araujo HS $^{3}$ and Sergio Eduardo Perez ${ }^{3}$ \\ ${ }^{1}$ Department of physical education and human motricity, Federal University of São Carlos, São Carlos/SP, Brazil \\ ${ }^{2}$ Department of education and health, Federal University of Sergipe, Lagarto/SE, Brazil \\ ${ }^{3}$ Department of physiological sciences, Federal University of São Carlos, São Paulo/SP, Brazil \\ ${ }^{4}$ Postgraduate education in Human Motricity Sciences, Department of physical education, São Paulo State Univer- \\ sity, Rio Claro/SP, Brazil \\ ${ }^{5}$ Department of Clinical Analysis, School of Pharmaceutical Sciences, São Paulo State University, Araraquara/SP, \\ Brazil
}

Received: 20 May, 2017; Accepted: 22 June, 2017; Published: 28 June, 2017

*Corresponding author: : Natalia Santanielo Silva Magosso, Department of physical education and human motricity, Federal University of São Carlos, São Carlos/SP Brazil. Tel: +55 16 99770-5343; E-mail: nataliasantanielo@gmail.com

\begin{abstract}
Exercise is known to increase the concentrations of irisin a remarkable myokine that may play an important protective role against metabolic disorders.

Propose: This study investigated the effects of irisin signaling pathway induced by Resistance Training (RT) in ovariectomized (Ovx) rats.

Methods: Thirty-two Holztman rats were randomly distributed to four experimental groups: Sham-Sedentary (Sed); Ovx-Sed; Sham-RT and Ovx-RT. The RT protocol demanded from the animals a vertical climb. Each session consisted of 4 to 12 climbs with $2 \mathrm{~min}$. of rest during 12 weeks. To quantify mRNA expression the $\Delta \Delta \mathrm{Ct}$ method was applied, protein expression was verified by Western Blotting and the analysis of irisin was determined by ELISA. When group averages were different $(\mathrm{p} \leq 0.05)$, a Tukey post-hoc test was applied.
\end{abstract}

Results: The Ovx-RT group had higher expression of PGC1 $\alpha$ FNDC5, irisin levels, and UCP1 compared to Ovx-Sed.

Conclusion: RT was led to higher expression of the irisin signaling pathway in the Ovx group showing that the RT seems to be an excellent strategy to counteract the ovariectomy-induced metabolic disorders.

Keywords: PGC1-A, FNDC5; Adipose Tissue; UCP1; Resistance Training

\section{Introduction}

Reduction of estrogen levels, a physiological status of female aging, causes problematic deleterious effects, such as loss of muscle mass, changes in fat mass, with the possibility of developing obesity [1-3]. This is a very important issue for public health, once obesity is associated with increased risk of cardiovascular disease and type 2 diabetes [3-5]. In experimental studies with rats, menopause is simulated by ovariectomy, which leads to effects such as loss of muscle mass and increased body and fat mass [6-8].
Physical exercise can be used as an intervention to improve the health of postmenopausal women given that that Resistance Training (RT) has been associated to decreases in fat mass and increases in lean body mass to prevent sarcopenia, cardiovascular diseases, type 2 diabetes and obesity [9-14]. These benefits occur in part because skeletal muscle is an endocrine organ and exercise stimulates skeletal muscle to produce and release myokines, which have endocrine functions [15]. Irisin is a remarkable myokine and its concentration seems to increase in response to both endurance training and RT [16-20]. During physical exercise, the release of this moykine is induced by the activation of PPAR $\gamma$ co-activator 1 alpha (PGC1- $\alpha$ ), which stimulates the fibronectin type III domain containing 5 (FNDC5) to cleave and release irisin into the blood [16].

Irisin is bound to unidentified receptors in the surface of white fat adipocytes and positively regulates the release of UCP1 (Uncoupling Protein 1), which provokes uncoupling in mitochondrial respiration and loss of energy in the form of heat and browning of the White Adipose Tissue (WAT) [16,21,22]. In addition, irisin could stimulate energy expenditure through modulation of hypothalamic neuropeptides and neurotransmitters involved in feeding control [23]. Thus, the thermogenic changes in white adipose tissue may play an important protective role against metabolic disorders, such as cardiovascular diseases, type-2 diabetes and obesity [24,25]. In view of these benefits, the activation of the irisin pathway could play an important protective role against the deleterious effects caused by reduced levels of estrogen. However, to date there are no studies that demonstrate the effect of RT on the irisin signaling pathway in Ovariectomized (Ovx) rats. Our hypotheses in the present study were: 1) the irisin signaling pathway would be lower in Ovx rats, and 2) the Sham and Ovx rats would have greater irisin signaling pathway after RT. 


\section{Methods}

\section{Animals and Experimental Conditions}

This study used 32 female Holtzman rats. During the experimental period, animals were kept in collective cages. Their environment was controlled by reversed light cycle $(12 \mathrm{~h}$ light cycle starting at 08:00 PM), at constant temperature $\left(22 \pm 2^{\circ} \mathrm{C}\right)$ and water and chow ad libitum. The study was approved by Ethics Commission of Animals Use-UFSCar (protocol n. 005/2013). All procedures were conducted according to the Guide for the Care and Use of Laboratory Animals [26].

\section{Experimental Groups}

Rats were randomly distributed into four experimental groups as follows: 1) Sham-operated (Sham) Sedentary (Sed) (Sham-Sed); 2) Ovariectomized (Ovx) Sedentary (Ovx-Sed); 3) Sham Resistance Training (Sham-RT); 4) Ovariectomized Resistance Training (Ovx-RT). Rats first underwent a bilateral ovariectomy or a bilateral sham operation. Thereafter, one group of Ovx and one group of Sham rats remained sedentary while one group of Ovx and one group of Sham rats were submitted to a 12-week RT program.

\section{Surgery}

Ovariectomy and sham surgeries were performed when animals reached $\sim 250$ g body weight. Surgical procedures were performed as described by Kalu [6]. Animals were anesthetized with an intra peritoneal mixture of ketamine-zylazine (61.5-7.6 $\mathrm{mg} / \mathrm{kg}$ ). The Ovx groups had their ovaries removed and sham groups only had their ovaries exposed. All animals had 1 week of recovery after surgery and 92 days of from surgery to euthanasia, that is, all rats were euthanized at 26 weeks of age.

\section{Resistance Training (RT)}

RT was performed in a vertical ladder with a cage at the top where animals rested for $2 \mathrm{~min}$ between climbs [27]. Three $50 \mathrm{ml}$ Falcon tubes containing weights were attached to their tails with adhesive tape as overload apparatus. Two familiarization sessions were performed. The rats were considered familiarized when they performed three consecutive climbs. Maximum Load was tested the first day after familiarization. The first climb was realized with an overload corresponding to $75 \%$ of animal's body weight and additional climbs with systematic increases of $30 \mathrm{~g}$ were performed until the rat was unable to climb the entire ladder even after three successive small stimuli in the tail. The larg- est successful load was considered the Maximum Carrying Load (MCL). Training sessions were performed every three days and consisted of four climbs with $50 \%, 75 \%, 90 \%$ and $100 \%$ of the MCL determined on the previous session. From the $5^{\text {th }}$ to the $9^{\text {th }}$ climb load was added $30 \mathrm{~g}$ until a new MCL was determined [27]. This pattern was made for 12 weeks in a total of 27 sessions of RT.

\section{Euthanasia and tissue collection}

At the end of the experimental period, animals were euthanized by decapitation. RT groups were euthanized $48 \mathrm{~h}$ after the last training session. Left gastrocnemius muscle, mesenteric fat, uterus and blood were taken, weighted and stored. Both the muscle tissue and fat were initially stored in liquid nitrogen and they were frozen at $-80 \mathrm{oC}$. For blood analysis, $8 \mathrm{~mL}$ of blood were collected, of which $4 \mathrm{~mL}$ were placed in a $13 \times 75 \mathrm{~mm}$ vacuum tube with EDTA k3, mixed with gentle inversions and centrifuged at $3000 \mathrm{rpm}$ for $10 \mathrm{~min}$. at $4^{\circ} \mathrm{C}$. The obtained plasma was taken and stored at $-20^{\circ} \mathrm{C}$. The remaining of the blood was put in a $15 \mathrm{~mL}$ falcon tube, mixed with gentle inversions and centrifuged at 3000 rpm for $10 \mathrm{~min}$. at $4^{\circ} \mathrm{C}$. The obtained serum was withdrawn and stored at $-20^{\circ} \mathrm{C}$.

\section{Quantitative Real-time polymerase chain reaction (RT- PCR)}

Total RNA was extracted with Trizol Invitrogen (Carlsbad, California, USA) according to manufacturer's recommendation. Briefly, $100 \mathrm{mg}$ of tissue were placed in $1 \mathrm{~mL}$ of Trizol and homogenized with the tissue homogenizer (Polytron - Fisher Scientific). Quantification of RNA was made by spectrophotometry (NanoDrop 2000 - Thermo Scientific, Waltham, Massachusetts, USA) with $1 \mu$ l of each sample. All used samples had the $260 \mathrm{~nm} / 280 \mathrm{~nm}$ ratio [28]. RT-PCR was performed in duplicate for each gene using a CFX 96 real-time PCR detection system (Bio-Rad, San Francisco, Calif., USA). All steps followed the manufacturer's recommendation and stored at $-20^{\circ} \mathrm{C}$. Reactions were made in $15 \mu \mathrm{l}$ of solution containing $1 \mu \mathrm{l}$ of the sample cDNA, $0.5 \mu$ l of each primer sequence Forward and Reverse, $5.5 \mu$ l of RNAse-free diethyl pyrocarbonate treated water and $7.5 \mu$ of the EvaGreen PCR Master mix (dNTP, reaction buffer, TaqDNA polymerase and EvaGreen).The genes analyzed were PGC- $1 \alpha$, FNDC5 and UCP1. Glyceraldehyde-3-Phosphate dehydrogenase (GAPDH) was used as an endogenous control (Table 1). The relative expression of the quantitative RT-PCR products was determined by the $2^{-\Delta \Delta C \mathrm{t}}$ method [29].

\begin{tabular}{|c|c|c|c|}
\hline Table 1: & \multicolumn{3}{|c|}{} \\
\hline Gene & Forward Primer & Reverse Primer & Access number \\
\hline PGC-1 $\boldsymbol{\alpha}$ & GGCCCGGTACAGTGAGTGTT & ATTGCTCCGGCCCTTTCTT & NM_031347.1 \\
\hline FNDC5 & CTCTTCATGTGGGCAGGTGTC & GCTGGTCTCTGATGCACTCTTG & NM_001270981.1 \\
\hline UCP1 & GGCATCCAGAGGCAAATCAGC & CCAATGAATACCGCCACGCC & NM_012682.2 \\
\hline GAPDH & GATGCTGGTGCTGAGTATGTCG & GTGGTGCAGGATGCATTGCTGA & NM_017008.3 \\
\hline
\end{tabular}

PGC-1 $\alpha$ : Peroxisome Proliferator-Activated Receptor-Gamma Coactivator 1 alpha; FNDC5: Fibronectin type III Domain-Containing protein 5; UCP1: Uncoupling Protein 1; GAPDH: Glyceraldehyde-3-Phosphate Dehydrogenase 


\section{Western Blotting assay}

Protein analyzes were performed by the Western blotting method [30]. Aliquots of gastrocnemius muscle and mesenteric fat $(\sim 100 \mathrm{mg})$ were separated by SDS-PAGE gel and transferred to nitrocellulose membrane. Before either procedure, the membrane was blocked with albumin solution 5\%. After this, each membrane was incubated overnight at $4^{\circ} \mathrm{C}$ with appropriate dilutions of primary antibodies, including FNDC5 (\#174833 - Abcam $($ ), UCP1 (\#23841- Abcam $®)$ and GAPDH (\#8245 - Abcam $®)$ and $\beta$-actin (\#4970 - Cell Signaling Technology $囚)$. The membrane was washed in TBST $(3 \times 5 \mathrm{~min}$.) and then incubated with the appropriate secondary antibody conjugated with HRP for 120 min. at room temperature. Antibody binding was detected by enhanced Super Signal ${ }^{\circledR}$ West Pico Chemiluminescent Substrate (PIERCE, IL, USA), as described by the manufacturer. Blots were scanned (Epson Expression 1600), and the densitometry of protein bands was determined by pixel intensity using Scion Image (Scion Corporation ${ }^{\circledR}$, Frederick, Maryland, USA).

\section{Elisa Assay}

Quantification and measurement of irisin was per- formed using Irsin enzyme-linked immunosorbent assay (ELISA) Kit (EK-067-16, Phoenix Pharmaceuticals, CA, USA) and microreader [20]. 17 $\beta$-Estradiol dosage was made with the commercial kit according to manufacturer's specifications (ADI-900-174, Enzo Life Sciences, Farmingdale, New York, USA). Assay sensibility was $10 \mathrm{pg} / \mathrm{mL}$. All samples were tested in duplicate. Quantification was given in relation to the standard curve using logistic 4-parameter nonlinear regression.

\section{Statistical Analysis}

Results were submitted to the Shapiro-Wilk normality test. As variables presented normal distribution, the one-way analysis of variance (ANOVA) was applied. When group averages were different ( $p \leq 0.05)$, Tukey post-hoc analysis was used. Statistical analyses were made using the software SPSS Statistics 17.0. Results are presented in mean \pm Standard Deviation (SD).

\section{Results}

The results of body weight, left gastrocnemius, mesenteric fat, $17 \beta$-Estradiol and uterus mass are presented in Table 2.

Table 2:

\begin{tabular}{|c|c|c|c|c|}
\hline Experimental Groups & Sham-Sed & Ovx-Sed & Sham-RT & Ovx-RT \\
\hline Body Weight (g) & $312.71 \pm 16.66$ & $373.98 \pm 20.70^{*}$ & $311.29 \pm 8.75$ & $355.93 \pm 15.44^{*} \& \#$ \\
\hline Left Gastrocnemius (g) & $1.56 \pm \mathbf{0 . 1 4}$ & $1.66 \pm \mathbf{0 . 1 2}$ & $1.65 \pm \mathbf{0 . 1 0}$ & $1.85 \pm \mathbf{0 . 1 0 ^ { * } \& \#}$ \\
\hline Mesenteric Fat (g) & $2.99 \pm \mathbf{0 . 0 6 4}$ & $3.45 \pm \mathbf{0 . 3 3}^{*}$ & $1.92 \pm 0.33^{*}$ & $3.08 \pm \mathbf{0 . 5 5}^{\&}$ \\
\hline $\mathbf{1 7 \beta}$-Estradiol (pg/ml) & $34.05 \pm 0.28$ & $14.91 \pm 0.56^{*}$ & $34.13 \pm 0.28$ & $14.63 \pm 0.51^{*} \&$ \\
\hline Uterus Mass (mg) & $0.65 \pm 0.14$ & $0.09 \pm 0.02^{*}$ & $0.62 \pm 0.06$ & $0.09 \pm 0.02^{*} \&$ \\
\hline
\end{tabular}

Data are presented as mean \pm SD. Sham: Sham operated; Ovx: Ovariectomized; RT: Resistance Training. $p \leq 0.05$ compared to the group * ShamSed; \& Sham-RT; \# Ovx-Sed,

Regarding the irisin pathway signaling, the ovariectomy induced lower ( $\mathrm{p} \leq 0.05$ ) PGC1- $\alpha$ mRNA expression (Figure 1) when compared with Sham-Sed group. The results of gene and protein expression of FNDC5 (Figure 2a and $2 \mathrm{~b}$ ) and irisin concentration (Figure 3) were not significantly different between Ovx-Sed and Sham-Sed groups. The final stepwise performed was UCP1 expression in mesenteric fat (Figure $4 \mathrm{a}$ and $4 \mathrm{~b}$ ) that was lower ( $\mathrm{p} \leq 0.05$ ) in the Ovx-Sed group when compared to the Sham-Sed group in both mRNA and protein expression, respectively.

The groups that performed RT presented higher ( $\mathrm{p} \leq$ 0.05) PGC1- $\alpha$ mRNA expression when compared to their sedentary control groups. The Ovx-RT group presented higher $(\mathrm{p} \leq$ 0.05) PGC1- $\alpha$ mRNA expression compared to Sham-Sed groups (Figure 1). FNDC5 mRNA expression (Figure 2a) was higher (p $\leq 0.05$ ) on trained animals compared to their sedentary control groups. The date of FNDC5 protein expression (Figure 2b) was also higher $(p \leq 0.05)$ on trained animals compared to their sedentary control groups.

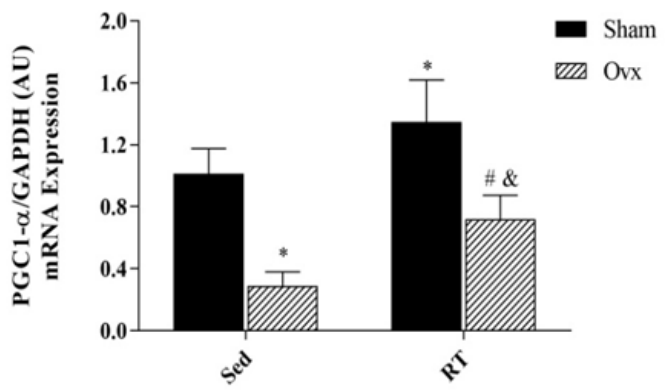

Figure 1: $1 \mathrm{PGC}-1 \alpha$ mRNA expression in the gastrocnemius muscle relative to GAPDH mRNA expression $(n=6)$. Values are mean \pm SD $(p$ $\leq 0.05$ ). Sham: sham-operated; Ovx: ovariectomized; Sed: sedentary; RT: resistance training. PGC-1 $\alpha$ : Peroxisome Proliferator-activated Receptor- $\gamma$ Coactivator- $1 \alpha$.

$*(\mathrm{p}<0.05)$ compared to Sham-Sed;

$\&(\mathrm{p}<0.05)$ compared to Sham-RT

\# $(\mathrm{p}<0.05)$ compared to Ovx-Sed. 


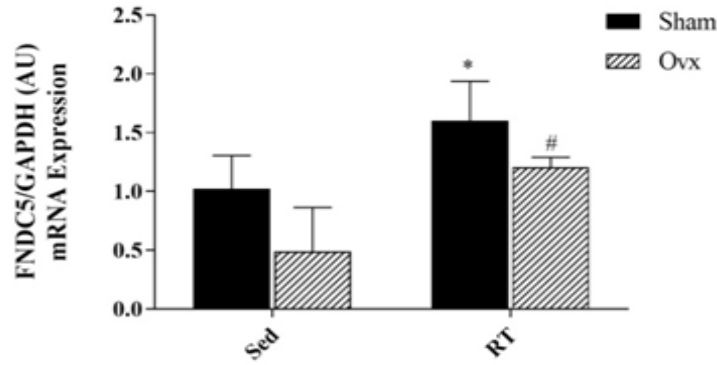

b

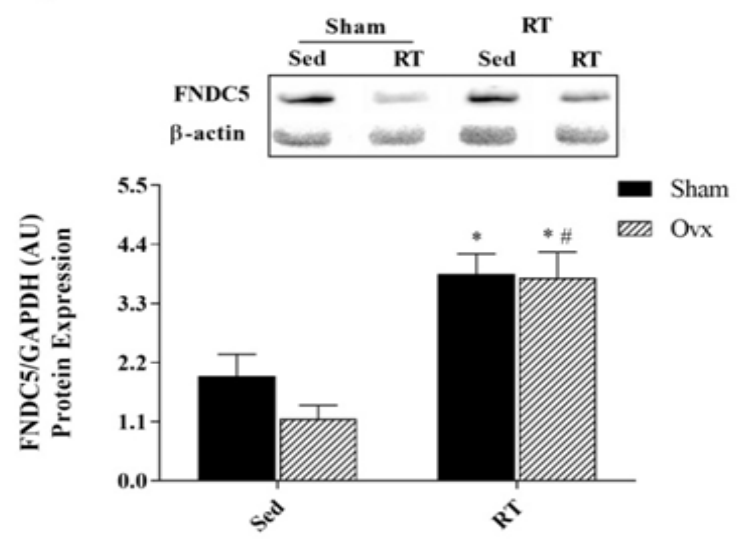

Figure 2: (a) FNDC5 mRNA expression relative to GAPDH mRNA expression $(\mathrm{n}=6)$. (b) FNDC5 protein expression relative to mRNA expression $(\mathrm{n}=$ $4)$ in the gastrocnemius muscle. Values are mean \pm SD ( $\leq 50.05)$. Sham: sham-operated; Ovx: ovariectomized; Sed: sedentary; RT: resistance training. FNDC5: Fibronectin type III domain-containing protein.

$*(\mathrm{p}<0.05)$ compared to Sham-Sed;

$\&(\mathrm{p}<0.05)$ compared to Sham-RT;

\# $(\mathrm{p}<0.05)$ compared to Ovx-Sed.

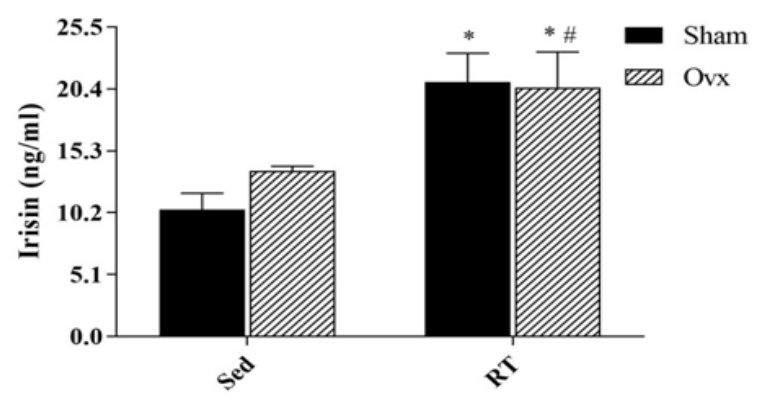

Figure 3: (a) Irisin Levels $(\mathrm{ng} / \mathrm{ml})$ in plasma $(\mathrm{n}=4)$. Values are mean $\pm \mathrm{SD}(p \leq 0.05)$. (b) Protein concentration bands of FNDC5/GAPDH and UCP1/ $\beta$-actin. Sham: sham-operated; Ovx: ovariectomized; Sed: sedentary; RT: resistance training.

$*(p<0.05)$ compared to Sham-Sed;

\# $(p<0.05)$ compared to Ovx-Sed.

Moreover, the Ovx-RT group had higher ( $\mathrm{p} \leq 0.05$ ) FNDC5 protein expression compared to the Sham-Sed. Although there was no significant difference between the Sham and Ovx groups for irisin plasma concentration (Figure 3), after 12 weeks of RT both trained groups presented higher $(\mathrm{p} \leq 0.05)$ irisin concentration when compared to their sedentary controls.

When Ovx-RT was compared to Sham-Sed group the irisin concentration was significantly higher $(\mathrm{p} \leq 0.05)$. UCP1 protein expression in mesenteric fat (Figure $4 \mathrm{~b}$ ) presented higher values ( $\mathrm{p} \leq 0.05$ ) in Sham-RT group compared to Sham-Sed. The
Ovx-RT group presented higher ( $\mathrm{p} \leq 0.05)$ mRNA and protein expression of UCP1 compared to the Ovx-Sed group. Finally, OvxRT presented higher $(\mathrm{p} \leq 0.05)$ protein expression of UCP1 compared to Sham-Sed (Figure 4).

\section{Discussion}

The main finding of the study was that the Ovx group submitted to RT had higher expression of the irisin signaling pathway, indicating the potential benefits of RT as an alternative strategy to control the deleterious effects of menopause. This is the first study to analyze the chronic effects of RT on irisin signaling pathway of Ovx rats.

\section{Ovariectomy}

In the present study, the highest body weight was found in the Ovx-Sed group (Table 1). Ovariectomized animals present body weight gain, and these effects indicate that estrogens play a pivotal role in preventing excess body weight gain in females [3135].

The results on gene expression of PGC1- $\alpha$ in the Ovx-Sed group represent that low estrogen levels could have a negative impact on skeletal muscle energy metabolism as mitochondria are estrogen-sensitive organelles [36]. This result corroborates with the findings of Barbosa, Shiguemoto, et al. which seems to be the first study to present some changes in mitochondrial function in an experimental model of menopause [37]. Our results strengthen the evidence that reduction of estrogen levels is a problem of female physiology that requires further investigation. Thus, our results suggest a link between ovariectomy and reduction of PGC1- $\alpha$ expression in the muscle. 


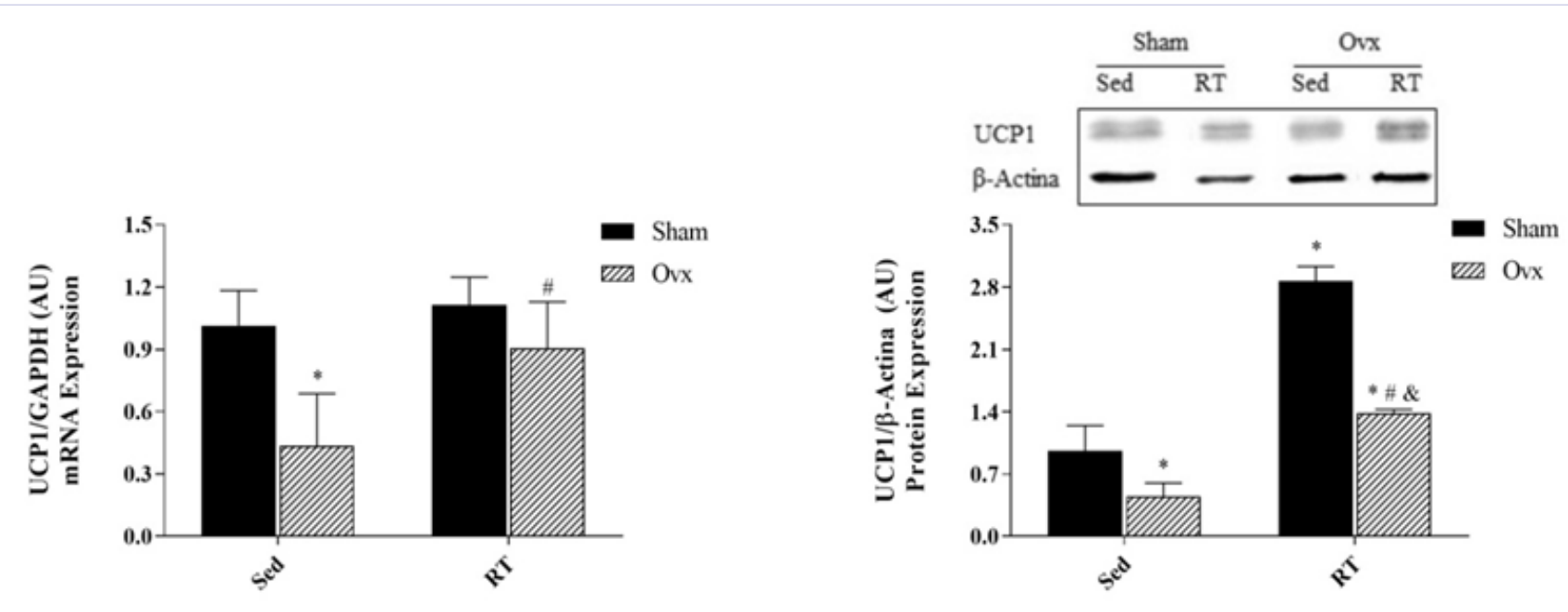

Figure 4: (a) UCP1 mRNA expression relative to GAPDH mRNA expression ( $\mathrm{n}=6$ ). (b) UCP1 protein expression relative to $\beta$-actin mRNA expression (n $=4)$ in the mesenteric fat. Values are mean $\pm \mathrm{SD}(p \leq 0.05)$. Sham: sham-operated; Ovx: ovariectomized; Sed: sedentary; RT: resistance training. UCP1: Uncoupling Protein.

$*(p<0.05)$ compared to Sham-Sed;

$\&(p<0.05)$ compared to Sham-RT:

\# $(p<0.05)$ compared to Ovx-Sed.

Regarding the results of gene and protein expression of FNDC5 and the levels of irisin in the Ovx-Sed group, we expected lower expression of the entire irisin pathway, however our hypothesis was not confirmed, since the Ovx-Sed group did not present lower expression of FNDC5 and levels of irisin when compared to Sham-Sed group. Tsuchiya, Ando, et al. assume that it is possible that another pathway is involved in this process however, more studies need to be conducted to discover such pathways [38]. FNDC5 has been discovered and characterized by Bostrom, $\mathrm{Wu}$, et al. nevertheless, other modulating factors of FNDC5 are not well known, although studies that analyze this membrane receptor are directly associated to PGC1- $\alpha$ and exercise [16,21]. Irisin is a recently discovered hormone and there is little evidence on factors that may modulate its signaling. Is well established in the literature that RT promotes irisin release, and also increases cellular thermogenesis and reduces fat storage by suppressing formation of new adipocytes [19,20,39-41]. Therefore, maintaining optimal irisin concentrations seems to be important, especially in our ovariectomy model, which has strong evidences of being a precursor of obesity and other metabolic disorders [42-45]. We found that the Ovx-Sed group presented similar values of irisin levels when compared to Sham-Sed group (Figure 3). However, it is already known that irisin increases cellular thermogenesis by up regulating UCP1, thus it is important to analyze and consider the UCP1 concentrations in WAT $[41,46]$.

The results of UCP1 gene and protein expression in mesenteric fat of the Ovx-Sed group (Figure 4a,b) were lower when compared to the Sham group. This result shows part of the deleterious effects caused by reduced estrogen, once UCP1 expression is related to changes in the thermogenesis of WAT [24]. Nowadays, there are no studies in the literature that show these results, however, according to Pedersen, Bruun, et al. ovariectomy induces lower expression of the UCP1 gene in BAT [47]. Furthermore, our study confirms these findings on the effects of ovariectomy leading to lower UCP1 expression in the WAT of Ovx-Sed rats. Our results show that in the Ovx-Sed group, even in normal irisin concentrations it does not produce the same stimulatory effect of UCP1 expression. As demonstrated in a previous study, the lower expression of UCP1 in brown adipose tissue seems to be associated with reduced levels of estrogen in rats [47]. Our study is the first to demonstrate that despite the fact that irisin levels are not impaired by the reduction of estradiol, UCP1 expression is reduced in Ovx-Sed rats. Thus, we can speculate that the OvxSed group did not have a thermogenic effect of WAT, once body and mesenteric fat weights were significantly greater compared to the Sham-Sed group (Table 2).

\section{Resistance Training}

12 weeks of RT were effective in leading to higher expression of the irisin signaling pathway in Sham and Ovx groups. Our study showed that the ovariectomy-induced reduction of estrogen levels leads to lower expression of PGC1- $\alpha$ and UCP1. However, RT yielded significantly higher the expression of PGC1- $\alpha$ as well as UCP1 in Ovx-RT. Our results corroborate with the findings of Barbosa, Shiguemoto, et al. that also reported lower PGC1- $\alpha$ in Ovx rats and their study showed that the reduction of PGC1- $\alpha$ expression are accompanied by significant reductions in genes and proteins as TFAM and NRF1, which favor mitochondrial biogenesis and also improve the thermogenic machinery [37,48-50]. These data represent an important contribution to understand the relation of exercise, higher mitochondrial biogenesis and thermogenic process as important strategy to prevent the effects of ovariectomy and development of some obesity-related dis- 
eases. In addition, studies showed that RT increases circulating irisin human and mice. Kim, Lee, et al. demonstrated an increase in circulating plasma irisin in overweight/ obese adults after 8 weeks of RT [19]. In a study with aging mice, Kim, et al. So demonstrated that circulating irisin was significantly increased after 12 weeks of RT [20]. The results of the present study evidence the benefits of RT for metabolic responses when estrogen levels are reduced. We also suggest that although ovariectomy does not interfere with irisin levels, RT is able to enhance the expression of factors related to the irisin signaling pathway in Ovx rats, once UCP1 expression in WAT was significantly higher in Ovx-RT compared to Ovx-Sed.

\section{Conclusion}

In summary, our hypothesis that RT would lead to higher expression of the irisin signaling pathway in both Sham and Ovx groups was confirmed. Thus, we conclude that RT seems to be an excellent strategy to counteract ovariectomy-induced metabolic disorders, since irisin signaling was not affected by ovariectomy. In addition, RT promotes alterations at UCP1 of WAT in ovariectomized rats, a crucial final stepwise of the whole irisin signaling pathway.

\section{Acknowledgement}

\section{Conflict of interest}

The authors do not have any conflict of interest related to this manuscript.

\section{Funding sources}

Financial support provided by Foundation of Supporting to Research of São Paulo State (FAPESP) Proc. n ${ }^{\circ} 2011 / 21607-$ 5 and Proc. $n^{\circ} 2013 / 06952-3$.

\section{References}

1. Maggio M, Lauretani F, Ceda GP. Sex hormones and sarcopenia in older persons. Curr Opin Clin Nutr Metab Care. 2013;16(1):3-13. doi: 10.1097/MC0.0b013e32835b6044

2. Saha KR, Rahman MM, Paul AR, Das S, Haque S, Jafrin W, et al. Changes in lipid profile of postmenopausal women. Mymensingh Med J. 2013;22(4):706-711.

3. Wietlisbach V, Marques-Vidal P, Kuulasmaa K, Karvanen J, Paccaud F, Project WM. The relation of body mass index and abdominal adiposity with dyslipidemia in 27 general populations of the WHO MONICA Project. Nutr Metab Cardiovasc Dis. 2013;23(5):432-442. doi: 10.1016/j. numecd.2011.09.002

4. Awa WL, Fach E, Krakow D, Welp R, Kunder J, Voll A, et al. Type 2 diabetes from pediatric to geriatric age: analysis of gender and obesity among 120,183 patients from the German/Austrian DPV database. Eur J Endocrinol. 2012;167(2):245-254.

5. Gregor MF, Hotamisligil GS. Inflammatory mechanisms in obesity. Annu Rev Immunol. 2011;29:415-445. doi: 10.1146/annurev-immunol-031210-101322

6. Kalu DN. The ovariectomized rat model of postmenopausal bone loss. Bone Miner. 1991;15(3):175-191.

7. Bunratsami S, Udomuksorn W, Kumarnsit E, Vongvatcharanon S, Vong- vatcharanon U. Estrogen replacement improves skeletal muscle performance by increasing parvalbumin levels in ovariectomized rats. Acta Histochem. 2015;117(2):163-175. doi: 10.1016/j.acthis.2014.12.003

8. Jung SR, Kim SH, Ahn NY, Kim KJ. Changes of bone metabolism based on the different interventions with exercise type or additional intake material in ovariectomized rats. J Exerc Nutrition Biochem. 2014;18(1):111-117. doi: 10.5717/jenb.2014.18.1.111

9. Wang $\mathrm{CH}$, Chung MH, Chan P, Tsai JC, Chen FC. Effects of endurance exercise training on risk components for metabolic syndrome, interleukin-6, and the exercise capacity of postmenopausal women. Geriatr Nurs. 2014;35(3):212-218. doi: 10.1016/j.gerinurse.2014.02.001

10. Nunes PR, Barcelos LC, Oliveira AA, Furlanetto Junior R, Martins FM, Orsatti CL, et al. Effect of resistance training on muscular strength and indicators of abdominal adiposity, metabolic risk, and inflammation in postmenopausal women: controlled and randomized clinical trial of efficacy of training volume. Age (Dordr). 2016;38(2):40. doi: 10.1007/ s11357-016-9901-6

11. Botero JP, Shiguemoto GE, Prestes J, Marin CT, Do Prado WL, Pontes $\mathrm{CS}$, et al. Effects of long-term periodized resistance training on body composition, leptin, resistin and muscle strength in elderly postmenopausal women. J Sports Med Phys Fitness. 2013;53(3):289-294.

12.Egana M, Reilly H, Green S. Effect of elastic-band-based resistance training on leg blood flow in elderly women. Appl Physiol Nutr Metab. 2010;35(6):763-772. doi: 10.1139/H10-071

13. Oliveira PF, Gadelha AB, Gauche R, Paiva FM, Bottaro M, Vianna LC, et al. Resistance training improves isokinetic strength and metabolic syndrome-related phenotypes in postmenopausal women. Clin Interv Aging. 2015;10:1299-1304. doi: 10.2147/CIA.S87036

14. Rossi FE, Fortaleza AC, Neves LM, Buonani C, Picolo MR, Diniz TA, et al. Combined Training (Aerobic Plus Strength) Potentiates a Reduction in Body Fat but Demonstrates No Difference on the Lipid Profile in Postmenopausal Women When Compared With Aerobic Training With a Similar Training Load. J Strength Cond Res. 2016;30(1):226-234. doi: 10.1519/JSC.0000000000001020

15. Pedersen BK, Febbraio MA. Muscles, exercise and obesity: skeletal muscle as a secretory organ. Nat Rev Endocrinol. 2012;8(8):457-465. doi: 10.1038/nrendo.2012.49

16. Bostrom P, Wu J, Jedrychowski MP, Korde A, Ye L, Lo JC, et al. A PGC1alpha-dependent myokine that drives brown-fat-like development of white fat and thermogenesis. Nature. 2012;481(7382):463-468. doi: 10.1038/nature10777

17. Huh JY, Mougios V, Kabasakalis A, Fatouros I, Siopi A, Douroudos II, et al. Exercise-induced irisin secretion is independent of age or fitness level and increased irisin may directly modulate muscle metabolism through AMPK activation. J Clin Endocrinol Metab. 2014;99(11):E2154-61. doi: 10.1210/jc.2014-1437

18. Norheim F, Langleite TM, Hjorth M, Holen T, Kielland A, Stadheim HK, et al. The effects of acute and chronic exercise on PGC- $1 \alpha$, irisin and browning of subcutaneous adipose tissue in humans. FEBS J. 2014;281(3):739-749. doi: 10.1111/febs.12619

19. Kim HJ, Lee HJ, So B, Son JS, Yoon D, Song W. Effect of aerobic training and resistance training on circulating irisin level and their association with change of body composition in overweight/obese adults: a pilot study. Physiol Res. 2016;65(2):271-279.

20. Kim HJ, So B, Choi M, Kang D, Song W. Resistance exercise training increases the expression of irisin concomitant with improved of muscle function in aging mice and human. Exp Gerontol. 2015;70:11-17. doi: 


\subsection{6/j.exger.2015.07.006}

21. Castillo-Quan JI. From white to brown fat through the PGC- $1 \alpha-$ dependent myokine irisin: implications for diabetes and obesity. Dis Model Mech. 2012;5(3):293-295. doi: 10.1242/dmm.009894

22. Arias-Loste MT, Ranchal I, Romero-Gomez M, Crespo J. Irisin, a link among fatty liver disease, physical inactivity and insulin resistance. International journal of molecular sciences. Int J Mol Sci. 2014;15(12):23163-23178. doi: 10.3390/ijms151223163

23. Ferrante C, Orlando G, Recinella L, Leone S, Chiavaroli A, Di Nisio C, et al. Central inhibitory effects on feeding induced by the adipomyokine irisin. Eur J Pharmacol. 2016;791:389-394. doi: 10.1016/j ejphar.2016.09.011

24. Moon HS, Mantzoros CS. Regulation of cell proliferation and malignant potential by irisin in endometrial, colon, thyroid and esophageal cancer cell lines. Metabolism. 2014;63(2):188-193. doi: 10.1016/j.metabol.2013.10.005

25. Sanchis-Gomar F, Lippi G, Mayero S, Perez-Quilis C, Garcia-Gimenez JL. Irisin: a new potential hormonal target for the treatment of obesity and type 2 diabetes. J Diabetes. 2012;4(3):196. doi: 10.1111/j.17530407.2012.00194.x

26. Institute of Laboratory Animal Resources (US). Committee on Care and Use of Laboratory Animals. Guide for the care and use of laboratory animals. NIH publication. Bethesda, Md.: U.S. Dept. of Health and Human Services, Public Health Service; 1996.

27. Hornberger TA Jr, Farrar RP. Physiological hypertrophy of the FHL muscle following 8 weeks of progressive resistance exercise in the rat. Can J Appl Physiol. 2004;29(1):16-31.

28. Sambrook J, Maniatis T, Fritsch EF. Molecular cloning : a laboratory manual. 2nd ed. Libraries Australia: Cold Spring Harbor, N.Y. : Cold Spring Harbor Laboratory Press, 1989.

29. Livak KJ, Schmittgen TD. Analysis of relative gene expression data using real-time quantitative PCR and the 2(-Delta Delta C(T)) Method. Methods. 2001;25(4):402-408.

30. Smith PK, Krohn RI, Hermanson GT, Mallia AK, Gartner FH, Provenzano MD, et al. Measurement of protein using bicinchoninic acid. Anal Biochem. 1985;150(1):76-85.

31. Matsushita H, Minami A, Kanazawa H, Suzuki T, Subhadhirasakul S, Watanabe $\mathrm{K}$, et al. Long-term supplementation with young coconut juice does not prevent bone loss but rather alleviates body weight gain in ovariectomized rats. Biomed Rep. 2017;6(5):585-591. doi: $10.3892 / \mathrm{br} .2017 .883$

32. Iwasa T, Matsuzaki T, Yano K, Yanagihara R, Tungalagsuvd A, Munkhzaya $\mathrm{M}$, et al. The effects of chronic testosterone administration on body weight, food intake, and adipose tissue are changed by estrogen treatment in female rats. Horm Behav. 2017;93:53-61. doi: 10.1016/j.yhbeh.2017.05.008

33. Rodrigues MFC, Ferreira FC, Silva-Magosso NS, Barbosa MR, Souza MVC, Domingos MM, et al. Effects of resistance training and estrogen replacement on adipose tissue inflammation in ovariectomized rats. Appl Physiol Nutr Metab. 2017;42(6):605-612. doi: 10.1139/apnm2016-0443

34. Hirschberg AL. Sex hormones, appetite and eating behaviour in women. Maturitas. 2012;71(3):248-56. doi: 10.1016/j.maturitas.2011.12.016

35. Asarian L, Geary N. Sex differences in the physiology of eating. Am J Physiol Regul Integr Comp Physiol. 2013;305(11):R1215-67. doi 10.1152/ajpregu.00446.2012
36. Chen JQ, Delannoy M, Cooke C, Yager JD. Mitochondrial localization of ERalpha and ERbeta in human MCF7 cells. Am J Physiol Endocrinol Metab. 2004;286(6):E1011-22.

37. Barbosa MR, Shiguemoto GE, Tomaz LM, Ferreira FC, Rodrigues MF, Domingues MM, et al. Resistance Training and Ovariectomy: Antagonic Effects in Mitochondrial Biogenesis Markers in Rat Skeletal Muscle. Int J Sports Med. 2016;37(11):841-848.

38. Tsuchiya Y, Ando D, Takamatsu K, Goto K. Resistance exercise induces a greater irisin response than endurance exercise. Metabolism. 2015;64(9):1042-1050. doi: 10.1016/j.metabol.2015.05.010

39. Ellefsen S, Vikmoen O, Slettalokken G, Whist JE, Nygaard H, Hollan I, et al. Irisin and FNDC5: effects of 12-week strength training, and relations to muscle phenotype and body mass composition in untrained women. Eur J Appl Physiol. 2014;114(9):1875-88. doi: 10.1007/ s00421-014-2922-x

40. Wu J, Cohen P, Spiegelman BM. Adaptive thermogenesis in adipocytes: is beige the new brown? Genes Dev. 2013;27(3):234-50. doi: 10.1101/ gad.211649.112

41. Zhang Y, Xie C, Wang H, Foss RM, Clare M, George EV, et al. Irisin exerts dual effects on browning and adipogenesis of human white adipocytes. Am J Physiol Endocrinol Metab. 2016;311(2):E530-41.

42. Andersson T, Soderstrom I, Simonyte K, Olsson T. Estrogen reduces 11beta-hydroxysteroid dehydrogenase type 1 in liver and visceral, but not subcutaneous, adipose tissue in rats. Obesity (Silver Spring). 2010;18(3):470-475. doi: 10.1038/oby.2009.294

43. Stotzer US, Rodrigues MF, Domingos MM, Silva GH, Duarte FO, Gatto $\mathrm{CV}$, et al. Resistance training suppresses intra-abdominal fatty acid synthesis in ovariectomized rats. Int J Sports Med. 2015;36(3):226233. doi: $10.1055 / \mathrm{s}-0034-1390494$

44. Panneerselvam S, Packirisamy RM, Bobby Z, Elizabeth Jacob S, Sridhar MG. Soy isoflavones (Glycine max) ameliorates hypertriglyceridemia and hepatic steatosis in high fat-fed ovariectomized Wistar rats (an experimental model of postmenopausal obesity). J Nutr Biochem. 2016;38:57-69. doi: 10.1016/j.jnutbio.2016.08.007

45. Losurdo P, Grillo A, Panizon E, Zanetti M, Bardelli M, Biolo G, et al. Baroreflex sensitivity and central hemodynamics after omega- 3 polyunsaturated fatty acids supplementation in an animal model of menopause. Vascul Pharmacol. 2015;71:65-69. doi: 10.1016/j.vph.2014.12.005

46. Divakaruni AS, Brand MD. The regulation and physiology of mitochondrial proton leak. Physiology (Bethesda). 2011;26(3):192-205. doi: 10.1152/physiol.00046.2010

47. Pedersen SB, Bruun JM, Kristensen K, Richelsen B. Regulation of UCP1, UCP2, and UCP3 mRNA expression in brown adipose tissue, white adipose tissue, and skeletal muscle in rats by estrogen. Biochem Biophys Res Commun. 2001;288(1):191-197.

48. Jeremic N, Chaturvedi P, Tyagi SC. Browning of White Fat: Novel Insight Into Factors, Mechanisms, and Therapeutics. J Cell Physiol. 2017;232(1):61-68. doi: 10.1002/jcp.25450

49. Rachid TL, Penna-de-Carvalho A, Bringhenti I, Aguila MB, Mandarimde-Lacerda CA, Souza-Mello V. Fenofibrate (PPARalpha agonist) induces beige cell formation in subcutaneous white adipose tissue from diet-induced male obese mice. Mol Cell Endocrinol. 2015;402:86-94 doi: 10.1016/j.mce.2014.12.027

50. Gomez-Hernandez A, Beneit N, Diaz-Castroverde S, Escribano O. Differential Role of Adipose Tissues in Obesity and Related Metabolic and Vascular Complications. Int J Endocrinol. 2016;2016:1216783. 